\title{
ALTERAÇÕES NA FOTOSSÍNTESE E NA TRANSPIRAÇÃO DE FOLHAS DE MILHO INFETADAS POR Phaeosphaeria maydis
}

\author{
CLÁUDIA V. GODOY, LILIAN AMORIM \& ARMANDO BERGAMIN FILHO
}

\author{
Departamento de Entomologia, Fitopatologia e Zoologia Agrícola, Escola Superior de Agricultura "Luiz de Queiroz", \\ Universidade de São Paulo, Cx. Postal 9, CEP 13418-900, Piracicaba, SP, fax (019) 434-4839; e-mail \\ liamorim@carpa.ciagri.usp.br
}

(Aceito para publicação em 10/04/2001)

Autor para correspondência: Lilian Amorim

GODOY, C.V., AMORIM, L. \& BERGAMIN FILHO, A. Alterações na fotossíntese e na transpiração de folhas de milho infetadas por Phaeosphaeria maydis. Fitopatologia Brasileira 26:209-215. 2001.

\section{RESUMO}

O efeito da mancha foliar de Phaeosphaeria, causada por Phaeosphaeria maydis, na taxa líquida de fotossíntese e na transpiração de folhas de milho (Zea mays) foi avaliado no campo em três híbridos e uma linhagem de milho. A taxa líquida de fotossíntese foi relacionada à severidade da doença por meio do modelo $P_{\mathrm{x}} / P_{\mathrm{o}}=(1-x)^{\beta}$, onde $P_{\mathrm{x}}$ representa a taxa fotossintética líquida de folhas com severidade de doença $x$ (em proporção), $P_{\mathrm{o}}$ representa a taxa fotossintética líquida média de folhas sadias e $\beta$ representa a relação entre a lesão virtual (área foliar com fotossíntese nula) e a lesão visual (área foliar coberta por sintomas). O parâmetro $\beta$ caracteriza o efeito do patógeno em toda a gama de severidade de doença.
Os valores de $\beta$ determinados por regressão não-linear $\left(R^{2}\right.$ de 0,73 a 0,85 para os diferentes materiais) variaram entre 2,46 e 2,69. Esses valores indicam que houve redução da eficiência fotossintética não apenas no tecido lesionado, mas também em parte do tecido verde remanescente de folhas infetadas. Folhas com severidade de doença no intervalo de 10-20\% mostraram reduções de $40 \%$ na taxa líquida de fotossíntese. A taxa de redução da transpiração foi proporcional à redução do tecido sadio. Houve relação linear negativa significativa $\left(R^{2}\right.$ de 0,59 a 0,75 para os diferentes materiais) entre a taxa de transpiração e a severidade da doença.

Palavras-chave: lesão virtual, eficiência fotossintética.

\section{ABSTRACT \\ Changes in photosynthesis and transpiration of corn leaves infected by Phaeosphaeria maydis}

The effect of Phaeosphaeria leaf spot, caused by Phaeosphaeria maydis, in the net photosynthetic rate and in the transpiration rate of maize (Zea mays) leaves was assessed under field condition, in three hybrids and one maize inbred. Photosynthetic rate was related to diseased leaf area by the model $P_{\mathrm{x}} / P_{\mathrm{o}}=(1-x)^{\beta}$, where $P_{\mathrm{x}}$ represents the net photosynthetic rate of a leaf with disease severity $x$ (in proportion), $P$ 。 represents the average net photosynthetic rate of healthy leaves, and $\beta$ is an expression of the ratio between virtual (leaf area where photosynthesis is nil) and visual lesion (leaf area covered by symptoms). Parameter $\beta$ characterizes the effect of the pathogen on the photosynthetic efficiency for the total range of measured disease severity. Values of $\beta$, determined by nonlinear regression analysis $\left(R^{2}\right.$ from 0.73 to 0.85 for the different material), ranged from 2.46 to 2.69 . These values indicated that the reduction in photosynthetic efficiency was detected not only in the lesioned tissue but also in part of the remaining green tissue of infected leaves. Reductions in net photosynthetic rate around $40 \%$ were observed to disease severity between 10 and $20 \%$. The reduction in transpiration rate was proportional to reduction of healthy leaf area due to disease. There was a negative linear relation ( $R^{2}$ from 0.59 to 0.75 for different materials) between transpiration rate and disease severity.
A mancha foliar de Phaeosphaeria, causada pelo ascomiceto Phaeosphaeria maydis (Henn.) Rane, Payak \& Renfro (anamorfo = Phoma maydis; Phyllosticta sp.), é uma doença foliar do milho (Zea mays L.) largamente distribuída na América Central, América do Sul, Ásia e África (Rane et al., 1966). As lesões são inicialmente pequenas, verde-pálidas ou cloróticas, tornando-se, com o decorrer do tempo, necróticas com margens marrom-escuras. As lesões são arredondadas, medindo $0,3-2,0 \mathrm{~cm}$, e podem coalescer, tornando-se irregulares. Estruturas reprodutivas (peritécios e picnídios) podem ser observadas no centro das lesões (Shurtleff, 1980). A redução na produção resulta da redução da fotossíntese decorrente da área foliar lesionada. No entanto, o efeito da doença na taxa fotossintética nunca foi quantificado.

Para a maioria das doenças foliares, a fotossíntese líquida de folhas infettadas é reduzida desde a infecção pelo patógeno. Esta redução na atividade fotossintética pode ser causada por redução na interceptação da radiação (RI), 


\section{V. Godoy et al.}

resultante da perda de área foliar fotossintetizante (áreas necrosadas resultantes da ação do patógeno) e/ou pela diminuição da eficiência de uso da radiação interceptada (RUE), devido à redução da taxa fotossintética do tecido verde remanescente (alteração na difusão de $\mathrm{CO}_{2}$ na folha, alteração da relação de solutos entre as células do hospedeiro, etc.) (Johnson, 1987).

Em alguns patossistemas, a redução da área foliar pela lesão é o único mecanismo pelo qual os patógenos reduzem a taxa fotossintética do hospedeiro (Spitters et al.,1990; van Oijen, 1990). No entanto, em outros, a taxa fotossintética é reduzida também no tecido verde, aparentemente sadio, ao redor das lesões (Rabbinge et al., 1985; Bastiaans, 1991; Goodwin, 1992; Shtienberg, 1992; Bassanezi et al., 1997). Para determinar o tipo de efeito causado pelo patógeno, Bastiaans (1991) estabeleceu a função matemática $P_{x} / P_{0}=(1-$ $x)^{\beta}$ que relaciona severidade da doença $(x)$ e taxa fotossintética líquida relativa da folha $\left(P_{\mathrm{x}} / P_{\mathrm{o}}\right)$, onde $P_{\mathrm{x}}$ é a fotossíntese líquida da folha com severidade de doença $x$ e $P_{\text {o é a }}$ fotossíntese líquida média de folhas sadias. $O$ parâmetro $\beta$ representa a razão da lesão virtual (área foliar em que a fotossíntese é nula) pela lesão visual (área foliar com sintomas visíveis ou severidade). Valores de $\beta$ significativamente maiores que 1 demonstram que o patógeno reduz a taxa fotossintética no tecido verde remanescente.

A transpiração de folhas doentes pode ser maior ou menor que aquela de folhas sadias (Duniway \& Durbin, 1971; Shtienberg, 1992; Bassanezi et al., 1997). O aumento da transpiração pode ser ocasionado pela destruição da cutícula, pelo aumento da permeabilidade da membrana das células da folha e pela inibição do fechamento dos estômatos. A redução da transpiração pode ser resultante do fechamento induzido dos estômatos pela doença, redução dos espaços do mesófilo pelas hifas ou hipertrofia das células do mesófilo, obstrução dos tecidos condutores e estômatos, desfolha e/ou murcha e seca precoce das folhas.

Poucos autores descreveram as relações quantitativas entre intensidade de doença e mudança na taxa de fotossíntese ou de transpiração. No patossistema arroz (Oryza sativa L.)Pyricularia grisea (Cooke) Sacc. essas variáveis foram incorporadas a simuladores de crescimento da cultura, promovendo melhor entendimento da redução da produção devido à doença (Bastiaans et al., 1994). Este trabalho teve como objetivo quantificar a relação entre taxa fotossintética e severidade de mancha de Phaeosphaeria, com base no modelo de Bastiaans (1991) e a relação entre transpiração e severidade da doença.

O efeito da mancha de Phaeosphaeria na eficiência fotossintética e na transpiração de folhas de milho foi avaliado em linhagem de milho, no campo experimental do Departamento de Genética da ESALQ/USP, em Piracicaba, São Paulo e em três híbridos de milho, na fazenda escola da Universidade Estadual de Ponta Grossa, em Ponta Grossa, Paraná. As avaliações foram realizadas sob condições naturais de epidemias em parcelas experimentais de cinco linhas de 10 metros conduzidas para vários estudos epidemiológicos.
Foram utilizadas a linhagem ESALQ PB2 e os híbridos XL 215, FT 5130 e FT 5150, sendo a linhagem avaliada no estádio 3 (planta com 12 folhas desdobradas) e os híbridos no estádio 5 (florescimento e polinização) da escala de Fancelli \& Lima (1982). Para avaliação da linhagem foi utilizada a quinta folha e para avaliação dos híbridos, a sétima folha.

Para avaliação das trocas gasosas das folhas sadias e doentes foi utilizado o medidor de trocas gasosas LI-6400 Portable Photosynthesis System (Li-Cor $\left.{ }^{\circledR}\right)$, que permite obter leituras instantâneas da taxa líquida de fotossíntese e da taxa de transpiração. Parte da folha avaliada foi inserida numa câmara ventilada de $6 \mathrm{~cm}^{2}$, sendo sua face superior iluminada pela luz do sol $\left(1200\right.$ - $2000 \mu \mathrm{mol} \mathrm{m} \mathrm{m}^{-2} \mathrm{~s}^{-1}$ de radiação fotossinteticamente ativa, sob condições de céu limpo) nas avaliações da linhagem ESALQ PB2 e do híbrido XL 215 e sob condições de luz artificial $\left(2000 \mu \mathrm{mol} \mathrm{m}^{-2} \mathrm{~s}^{-1}\right.$ de radiação fotossinteticamente ativa) nas avaliações dos demais híbridos. As folhas avaliadas foram escolhidas ao acaso em função do nível de severidade. Em cada folha, foram realizadas até quatro leituras em diferentes áreas. O número de leituras variou com o material analisado, sendo sempre superior a 140, com o objetivo de obter amostras que variassem de 0 até próximo a $100 \%$ de severidade.

A área foliar amostrada na análise de fotossíntese foi marcada e as folhas foram destacadas e levadas para laboratório para realizar a quantificação da área foliar lesionada, com o auxílio do medidor de área foliar LI-3000 Leaf Area Meter (Li-Cor $\left.{ }^{\circledR}\right)$. As áreas lesionadas foram desenhadas em plástico transparente, integralizadas e a severidade foi calculada pela divisão da área lesionada por 6 $\mathrm{cm}^{2}$ (área amostrada).

A relação entre severidade e taxa fotossintética líquida relativa (razão entre a taxa fotossintética líquida de folhas doentes e a taxa fotossintética líquida média de folhas sadias, $\left.P_{\mathrm{x}} / P_{\mathrm{o}}\right)$ foi determinada pelo modelo de Bastiaans (1991). De forma semelhante, foi calculada a taxa de transpiração relativa ( $T_{\mathrm{x}} / T_{\mathrm{o}}$, onde $T_{\mathrm{x}}$ representa a taxa de transpiração de folhas com severidade $x$ e $T_{0}$, a taxa de transpiração média das folhas sadias), sendo sua relação com a severidade de doença determinada por modelo linear. $O$ parâmetro $\beta$ do modelo de Bastiaans foi determinado por regressão não-linear e as análises de regressão linear foram realizadas no programa 'Statistica' (Stat-Soft, Tulsa, E.U.A.). Os parâmetros $\beta$, estimados para os diferentes materiais, foram comparados estatisticamente utilizando teste $\mathrm{t}$ (Campbell \& Madden, 1990). As inclinações das retas obtidas pela relação entre severidade e taxa de transpiração também foram comparadas pelo teste $\mathrm{t}$.

Folhas com ampla gama de severidade foram amostradas em todos os materiais avaliados (Figura 1). A redução na fotossíntese de folhas infetadas, expressa como uma fração da taxa fotossintética das folhas sadias, foi sempre superior à severidade da doença. A doença não reduziu somente a quantidade de área foliar como também afetou a fotossíntese no tecido foliar assintomático remanescente. Com o progressivo aumento da severidade, a redução na taxa 
fotossintética foi proporcionalmente maior que a redução da área foliar devido às lesões (Figura 1). Folhas com severidade em torno de 10-20\% apresentaram redução na taxa fotossintética líquida ao redor de $40 \%$.

O modelo de Bastiaans (1991) foi ajustado aos dados de taxa fotossintética líquida relativa e de severidade da doença (Figura 1a-d). Todas as regressões foram significativas $(\mathrm{P}<0.01)$ e os resíduos não apresentaram nenhuma tendência. Os parâmetros $\beta$ ( \pm erro padrão) estimados foram 2,56 ( \pm $0,11), 2,46( \pm 0,09), 2,52( \pm 0,11)$ e $2,69( \pm 0,11)$ para a linhagem ESALQ PB2 e para os híbridos XL 215, FT 5130 e FT 5150, respectivamente, não diferindo estatisticamente entre si ao nível de $5 \%$ de significância. Os coeficientes de determinação $\left(R^{2}\right)$ obtidos no ajuste do modelo para os diferentes ensaios variaram entre 0,73 e 0,85 , sendo semelhantes ou superiores aos valores obtidos em outros patossistemas (Bastiaans, 1991; Goodwin, 1992; Bassanezi et al., 1997), mostrando-se adequados para estudos realizados em campo. O parâmetro $\beta$ obtido na análise conjunta dos dados foi 2,55 $( \pm 0,05)$, com um coeficiente de determinação de 0,80 .

Embora as medições da taxa fotossintética líquida demonstrassem que a mancha de Phaeosphaeria reduziu a fotossíntese no tecido verde remanescente, essas medidas não esclareceram o mecanismo responsável pela redução nem indicaram a localização desse efeito.

Waggoner \& Berger (1987) argumentam que a radiação absorvida pela área verde sadia é adequada para explicar a produção na maioria dos patossistemas. A presença de tecido doente, segundo Johnson (1987) poderia, no entanto, influenciar o desenvolvimento da cultura por meio da redução da radiação solar interceptada (RI) pela área verde ou por meio da interferência na eficiência do uso da radiação (RUE). Este ensaio demonstrou que a mancha de Phaeosphaeria é um exemplo onde ambos efeitos ocorrem. Esse mesmo efeito já foi constatado para patossistemas como Erysiphe graminis - trigo [Triticum aestivum (L.) Thell.] (Rabbinge et al., 1985; Shtienberg, 1992), Magnaporthe grisea (Hebert) Yaegashi \& Udagawa - arroz (Bastiaans, 1991), Alternaria (Fr.:Fr.) Keissl.- algodoeiro (Gossypium spp.), Pestalotia mangiferae Henn. - mangueira (Mangifera indica L.), Mycosphaerella graminicola (Fuckell) Schroeter - trigo, Puccinia recondita Rob. ex Desm. - trigo, Puccinia sorghi Schw. - milho, Pseudoperonospora cubensis (Berk \& Curtis) Rostowzew abobrinha (Cucumis sativus L.), Leveillula taurica (Lev.) Arnaud. - pimenta (Capsicum annuum), Uncinula necator (Schw.) Burril - videira (Vitis vinifera L.), Sphaerotheca pannosa (Wallr.:Fr.) Lév. - pessegueiro (Prunus persica L.) (Shtienberg, 1992), Xanthomonas campestris pv. phaseoli (Smith) Dye - feijoeiro (Phaseolus vulgaris L.) (Goodwin, 1992) e Colletotrichum lindemuthianum (Sacc. \& Magn.) Br. \& Cav. - feijoeiro (Bassanezi et al., 1997).

A taxa de transpiração relativa mostrou decréscimos proporcionais aos incrementos de severidade, em todos os casos (Figura 2). O modelo linear foi ajustado aos dados, apresentando-se significativo, sem presença de tendência no resíduo e com coeficientes de determinação adequados $\left(R^{2}\right.$ entre 0,59 e 0,75$)$, considerando o elevado número de pontos
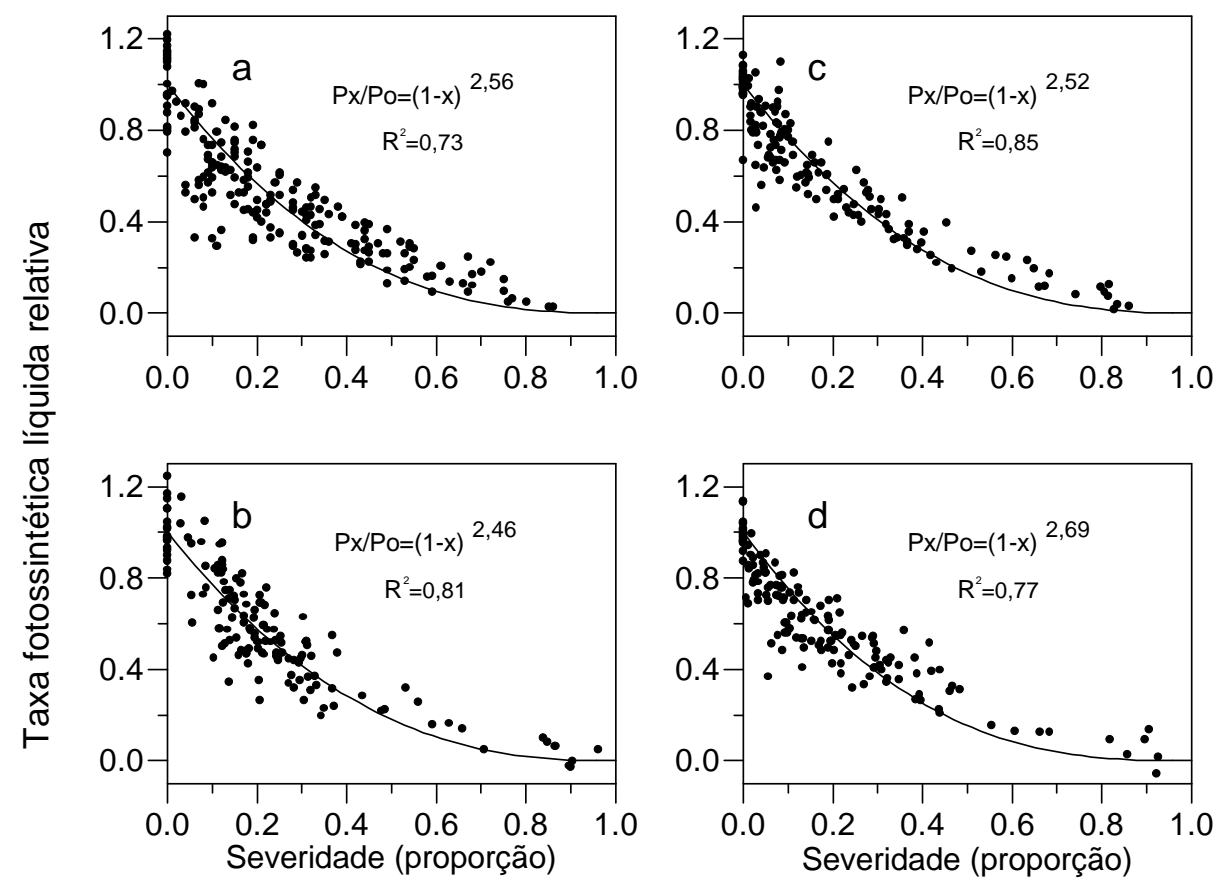

FIG. 1 - Efeito de diferentes severidades de mancha de Phaeosphaeria na taxa fotossintética líquida relativa $\left(P_{\mathrm{x}} / P_{0}\right)$ de folhas de milho (Zea mays), na linhagem ESALQ PB2 (a) e nos híbridos XL 215 (b), FT 5130 (c) e FT 5150 (d). 
C. V. Godoy et al.
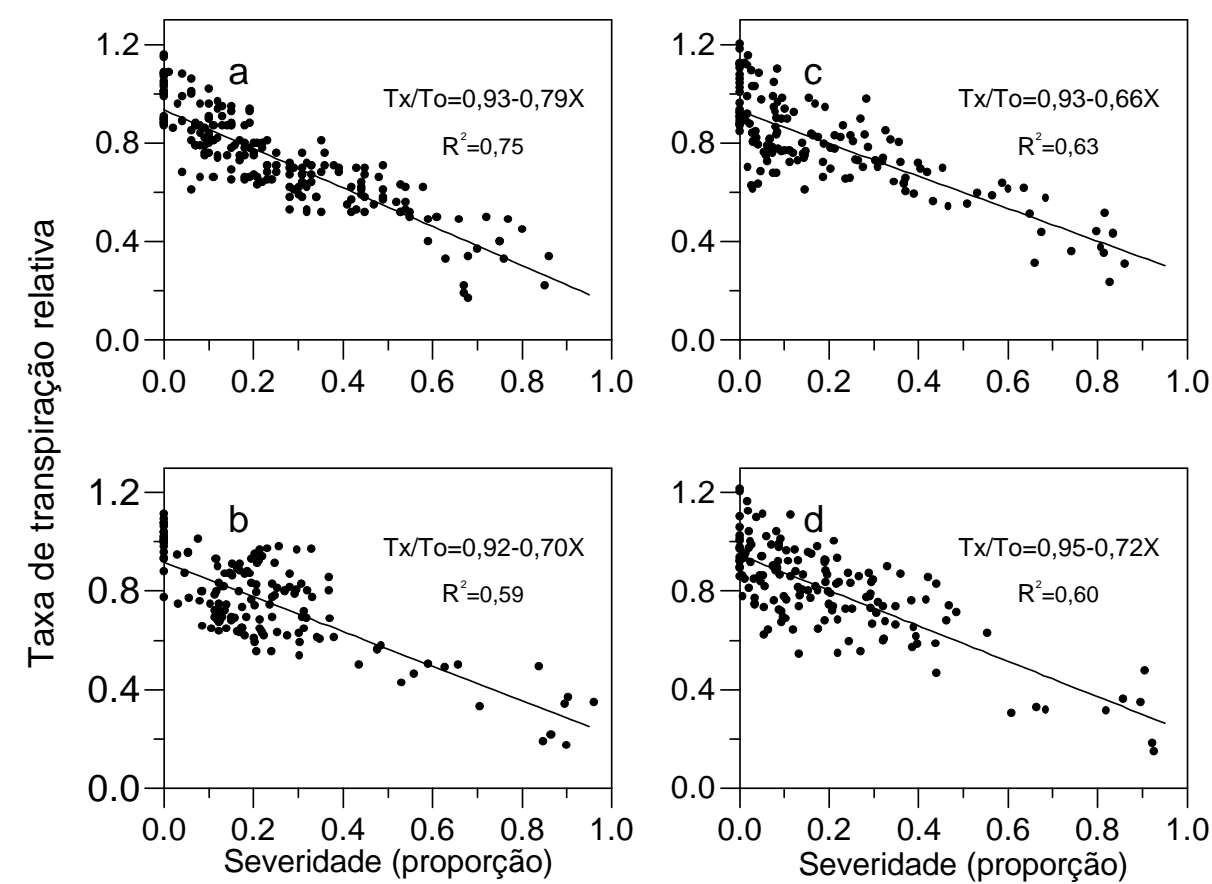

FIG. 2 - Efeito de diferentes severidades de mancha de Phaeosphaeria na taxa de transpiração relativa $\left(T_{x} / T_{0}\right)$ de folhas de milho, na linhagem ESALQ PB2 (a) e nos híbridos XL 215 (b), FT 5130 (c) e FT 5150 (d).

e o fato dos ensaios terem sido realizados no campo. As inclinações das retas, quando comparadas entre si pelo teste $t$, diferiram estatisticamente somente para os materiais ESALQ PB2 e FT 5130, sendo as demais iguais ao nível de $5 \%$ de significância. Relações severidade-transpiração inversamente proporcionais foram obtidas também por Shtienberg (1992) em patossistemas necrotróficos (A. alternata - algodoeiro, $P$. mangiferae - mangueira, $M$. graminicola - trigo). Segundo esse autor, as respostas do hospedeiro em relação às taxas fotossintéticas e de transpiração não estão relacionadas com o grupo sistemático do patógeno ou do hospedeiro mas podem ser relacionadas com o tipo de relação trófica existente entre eles.

Os resultados obtidos nestes ensaios demostraram que a simples quantificação visual da severidade da doença no patossistema $P$. maydis - milho não fornece uma indicação precisa do efeito do patógeno na taxa fotossintética do hospedeiro. No entanto, a taxa de transpiração apresentou correlação negativa proporcional à severidade visual da doença, sendo suficiente para explicar a redução nesse componente.

\section{REFERÊNCIAS BIBLIOGRÁFICAS}

BASSANEZI, R.B., MARTINS, M.C., GODOY, C., AMORIM, L. \& BERGAMIN FILHO, A. Efeito da antracnose na eficiência fotossintética do feijoeiro. Fitopatologia Brasileira 22:520-524. 1997.

BASTIAANS, L. Ratio between virtual and visual lesion size as a measure to describe reduction in leaf photosynthesis of rice due to leaf blast. Phytopathology 81:611-615.1991.
BASTIAANS, L., RABBINGE, R. \& ZADOKS, J.C. Understanding and modeling leaf blast effects on crop physiology and yield. In: Zeigler, R.S., Leong, S.A. \& Teng, P.S. (Eds.) Rice Blast Disease. Wallingford. CAB International. 1994. pp. 381-409

CAMPBELL, C.L. \& MADDEN, L.V. Introduction to Plant Disease Epidemiology. New York. John Wiley \& Sons. 1990.

DUNIWAY, J.M. \& DURBIN, R.D. Some effects of Uromyces phaseoli on the transpiration rate and stomatal response of bean leaves. Phytopathology 61:114-119. 1971.

FANCELLI, A.L. \& LIMA, V.A. Milho, Produção, Préprocessamento e Transformação Agroindustrial. Piracicaba. Série extensão agroindustrial 5. 1982.

GOODWIN, P.H. Effect of common bacterial blight on leaf photosynthesis of bean. Canadian Journal of Plant Pathology. 14:203-206. 1992.

JOHNSON, K.B. Defoliation, disease and growth: a reply. Phytopathology 77:1495-1497. 1987.

RABBINGE, R., JORRITSMA, I.T.M. \& SCHANS, J. Damage components of powdery mildew in winter wheat. Netherlands Journal of Plant Pathology 91:235-247. 1985.

RANE, M.S., PAYAK, M.M. \& RENFRO, B.L. A phaeosphaeria leaf spot of maize. Indian Phytopathological Society Bulletin 3:8-10. 1966.

SHTIENBERG, D. Effects of foliar disease on gas exchange process: a comparative study. Phytopathology 82:760765. 1992

SHURTLEFF, M.C. Compendium of Corn Diseases. $2^{\text {nd }}$ ed. 
St. Paul. APS Press. 1980.

SPITTERS, C.J.T., VAN ROERMUND, H.J.W., VAN NASSAU, H.G.M.G., SCHEPERS, J. \& MESDAG, J. Genetic variation in partial resistance to leaf rust in wheat: disease progress, foliage senescence and yield reduction Netherlands Journal of Plant Pathology 96:3-
15. 1990.

VAN OIJEN, M. Photosynthesis is not impaired in healthy tissue of blighted potato plants. Netherlands Journal of Plant Pathology 96:55-63. 1990.

WAGGONER, P.E. \& BERGER R.D. Defoliation, disease and growth. Phytopathology 77:393-398. 1987. 